\title{
Implementation of a Hospital-based Trauma Registry in Santa Cruz de la Sierra, Bolivia: Methodology, Preliminary Results, and Lessons learned
}

\author{
${ }^{1}$ Marissa A Boeck, ${ }^{2}$ Kevin J Blair, ${ }^{3} \mathrm{~J}$ Esteban Foianini, ${ }^{4}$ Henry B Perry, ${ }^{5}$ Lina V Mata, ${ }^{6}$ Michel B Aboutanos \\ ${ }^{7}$ Adil H Haider, ${ }^{8}$ Mamta Swaroop
}

\begin{abstract}
Aim: Five million annual global deaths are attributable to injuries. Yet, a lack of reliable data leaves the true magnitude of injuries unknown in many low- and middle-income countries (LMICs), like Bolivia. Trauma registries provide a means of acquiring these data. We sought to evaluate methodology, preliminary results, and lessons learned during the implementation of a pilot, hospital-based trauma registry at one facility in Santa Cruz de la Sierra, Bolivia.
\end{abstract}

Materials and methods: Data collection occurred from January to September 2015 at Clínica Foianini, a private, 50-bed, third-level facility in Santa Cruz. A paper trauma registry form based on the Panamerican Trauma Society's (ATS's) essential elements model was utilized. Trained nurses completed forms at a trauma patient's initial hospital presentation. Results were analyzed via descriptive statistics.

Results: The registry produced 91 forms over 8 months. An ICD-10 diagnosis code search of hospital visits showed 2,816 eligible patients, with a registry capture rate of $3.2 \%$. Most were males (59.3\%) in their mid-20s with head contusions (19.8\%), penetrating/lacerating upper extremity $(11.0 \%)$ or head $(7.7 \%)$ wounds, or upper extremity fractures (6.6\%). Many forms were missing critical data, with average omissions of 12.5 per form (26.0\% of questions) and 23.7 per question (26.0\% of subjects). Errors averaged 1.0 per form (2.1\% of questions) and 2.0 per question (2.2\% of subjects).

\footnotetext{
${ }^{1}$ Resident, ${ }^{2}$ Medical Student, ${ }^{3}$ Director, ${ }^{4}$ Senior Scientist ${ }^{5}$ International Fellow, ${ }^{6}$ Professor, Chair, and Medical Director ${ }^{7}$ Kessler Director, ${ }^{8}$ Assistant Professor
}

${ }^{1}$ Department of Surgery, New York Presbyterian Hospital Columbia, New York, USA

${ }^{2,8}$ Department of Trauma and Critical Care, Northwestern University Feinberg School of Medicine, Chicago, Illinois, USA

${ }^{3}$ Department of Surgery, Clínica Foianini, Santa Cruz de la Sierra, Santa Cruz, Bolivia

${ }^{4}$ Department of International Health, Johns Hopkins Bloomberg School of Public Health, Baltimore, Maryland, USA

${ }^{5,6}$ Department of Acute Care Surgery, Virginia Commonwealth University Medical Center, Richmond, Virginia, USA

${ }^{7}$ Department of Surgery and Public Health, Brigham and Women's Hospital, Boston, Massachusetts, USA

Corresponding Author: Marissa A Boeck, Resident Department of Surgery, New York Presbyterian Hospital Columbia, New York, USA, Phone: +0012123053038, e-mail: marissaboeckMD@gmail.com
Conclusion: Early efforts to implement a paper-based trauma registry at one Bolivian hospital highlight areas for improvement, mainly within education, training, and oversight. Lessons learned will inform long-term objectives to make the registry a standard hospital program across the city, and eventually throughout Bolivia, arming decision-makers with data for targeted trauma initiatives that save lives.

Clinical significance: These results provide insight into trauma registry implementation in LMICs, which serves to further inform the Bolivian program and can be applied to comparable initiatives in similar settings.

Keywords: Bolivia, Burden of injuries, Developing world, Health system strengthening, Injury prevention, Other, Public health, Quality improvement, Trauma registry.

How to cite this article: Boeck MA, Blair KJ, Foianini JE, Perry HB, Mata LV, Aboutanos MB, Haider AH, Swaroop M. Implementation of a Hospital-based Trauma Registry in Santa Cruz de la Sierra, Bolivia: Methodology, Preliminary Results, and Lessons learned. Panam J Trauma Crit Care Emerg Surg 2016;5(2):101-112.

Source of support: Nil

Conflict of interest: None

\section{RESUMEN}

Objetivo: Cinco millones de muertes anuales a nivel mundial son atribuibles a lesiones. Sin embargo, la falta de datos confiables deja la verdadera magnitud de las lesiones desconocida en muchos países de bajos y medianos ingresos (LMIC), como Bolivia. Los registros de trauma proporcionan un medio para adquirir estos datos. Buscamos evaluar la metodología, resultados preliminares y lecciones aprendidas durante la ejecución de una fase piloto, de un registro de trauma basado en una instalación hospitalaria situada en Santa Cruz de la Sierra, Bolivia.

Materiales y métodos: Los datos fueron recolectados desde Enero a Septiembre del 2015 en la Clínica Foianini, una organización privada, de 50 camas, de tercer nivel en Santa Cruz. Un formulario de trauma en papel basado en los elementos esenciales del registro de trauma de la Sociedad Panamericana de Trauma fue utilizado. Enfermeras entrenadas completaron los formularios en el hospital durante la llegada inicial al hospital de un paciente. Los resultados fueron analizados por medio de estadísticas descriptivas.

Resultados: El registro produjo un total de 91 formularios en más de 8 meses. Una búsqueda de diagnóstico según código de CIE-10 de las visitas al hospital demostró que 2.816 de los pacientes eran elegibles para el registro, con un rango de captura del registro del 3,2\%. La mayoría eran hombres (59,3\%) 
en sus mediados años 20 , con contusiones en la cabeza $(19,8 \%)$, lesiones penetrantes / lacerantes de la extremidad superior $(11,0 \%)$ o heridas de la cabeza $(7,7 \%)$ o fracturas de las extremidades superiores (6,6\%). Muchos formularios carecían de datos críticos, con un promedio de omisiones de 12,5 por formulario (26,0\% de las preguntas) y el 23,7 por pregunta (26,0\% de los sujetos). Errores en promedio 1.0 por formulario (el $2,1 \%$ de las preguntas) y 2,0 por pregunta (el $2,2 \%$ de los sujetos).

Conclusión: Los primeros esfuerzos para poner en práctica un registro de trauma basado en papel en un hospital de Bolivia, resalta las áreas que necesitan mejora, sobre todo dentro de la educación, la capacitación y la supervisión. Las lecciones aprendidas informarán objetivos a largo plazo para hacer el registro de un programa hospitalario en serie en toda la ciudad, y finalmente, en toda Bolivia, armando a los tomadores de decisiones con datos para iniciativas dirigidas a el trauma que salvara vidas.

Importancia clínica: Estos resultados arrojan a la luz, la aplicación de un registro de trauma en LMIC, que sirve para en un futuro informar al programa Boliviano que se puede aplicar a iniciativas comparables en entornos similares.

Palabras clave: Bolivia, carga de lesiones, mundo en desarrollo, fortalecimiento del sistema de salud, prevención de lesiones, Otros, salud pública, mejora de la calidad, registro de trauma.

\section{INTRODUCTION}

An estimated five million annual global deaths are attributable to injuries, with $90 \%$ occurring in low-resource settings. ${ }^{1,2}$ Tens of millions more likely suffer from nonfatal injuries. ${ }^{2}$ Traumas, thus, represent a significant global economic burden; estimates for the cost of injuries due to road traffic incidents (RTIs) alone approach $3 \%$ of a country's gross domestic product (GDP). ${ }^{3}$ Changing this trajectory requires preventative strategies informed by injury surveillance and risk factor identification. ${ }^{2}$

Alack of reliable data leaves the magnitude of the injury problem largely unknown in many low- and middleincome countries (LMICs), such as the Plurinational State of Bolivia (hereafter referred to as Bolivia). Trauma registries promise to fill this void by capturing information on patient and injury demographics, interventions at each stage of care, and outcomes. Registries also serve as a tool to oversee quality of care, monitor new interventions, calculate mortality risk, allocate resources, and inform preventative strategies. ${ }^{4}$ Despite widespread recognition of the value of trauma registries and their extensive adoption in developed countries, only 50 registries across 21 LMICs are documented in the literature. Amongst these, the capacity to address injury severity and patient outcomes varies significantly. ${ }^{5}$

Bolivia is a LMIC with a population of 10.6 million, a GDP per capita of only USD 3,124, ${ }^{6}$ and low ranks on many social and health indicators. ${ }^{7}$ The latter is likely to be related to small per-capita health care expenditures, with below average spending compared to surrounding countries. ${ }^{6}$ Like many LMICs, Bolivia lacks an integrated emergency response system, consistent injury surveillance, and coordinated trauma management networks. ${ }^{8}$ Limited available data suggest injury morbidity and mortality are higher in Bolivia than the regional average. According to the 2013 Global Burden of Disease (GBD) study, RTIs are the third leading cause of Disability Adjusted Life Years (DALYs) in Bolivia, with 1,377.5 years of life lost per 100,000 persons. ${ }^{9}$ The World Health Organization (WHO) estimates 23.2 annual road traffic deaths per 100,000 population in Bolivia, compared to the regional average of 15.9 deaths per 100,000. ${ }^{3}$ However, these numbers likely underestimate the true trauma burden due to an isolated focus on mortality caused by only one injury mechanism.

To begin improving the quality of injury data in Bolivia, we sought to implement a hospital-based trauma registry at one facility in the city of Santa Cruz de la Sierra. The methodology, preliminary results, and lessons learned from this pilot program will provide targets for process improvement, while also facilitating and motivating registry expansion to additional hospitals and regions within Bolivia. These efforts will ideally lead to more accurate national injury statistics, thus enabling informed policies and interventions that effectively aim to reduce the trauma burden.

\section{MATERIALS AND METHODS}

This pilot study took place from January to September 2015 in Santa Cruz de la Sierra, Bolivia. Institutional Review Board approval was obtained through Northwestern University (NU). Due to the absence of formal ethical research boards at the participating facility, we obtained local approval from Clínica Foianini and the Secretary of Health and Social Policy for the Autonomous Department of Santa Cruz.

\section{Study Location}

Bolivia, a land-locked country in South America, is divided into nine administrative departments. The geographically diverse department of Santa Cruz, whose capital is Santa Cruz de la Sierra (Map 1), borders Brazil to the east, Paraguay to the South, and is characterized by mountains, plains, and the Amazon river basin. ${ }^{10}$ The department boasts a population of 2.7 million, with nearly $82 \%$ living in urban areas, ${ }^{11}$ compared to $66 \%$ nationwide. ${ }^{7}$ It is also considered to be one of the most affluent regions of the country, which is linked to local oil production. ${ }^{12}$

Santa Cruz was chosen as the site for the current study due to strong local stakeholder engagement, and the presence of adequate infrastructure for the proposed program. The hospital selected for the pilot trauma 


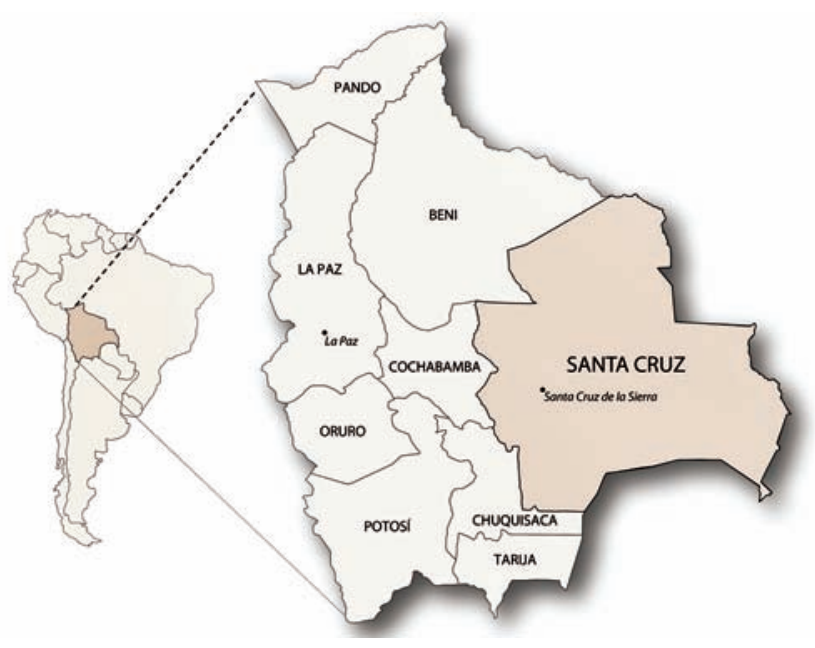

Map 1: The Plurinational State of Bolivia and its nine departments

registry was Clínica Foianini, a private, 50-bed, third-level facility in Santa Cruz de la Sierra. The hospital has nearly the equivalent of Level I trauma center status as per US criteria, with four operating rooms and radiology services (X-ray, ultrasound, and computed tomography) readily available. There are four general surgeons and numerous surgical subspecialty staff on-call; and emergency department (ED) physicians and nurses are all required to have Advanced Trauma Life Support (ATLS) certification.

\section{Trauma Registry Model}

The trauma registry model utilized in this study was developed by the Panamerican Trauma Society (PTS), an internationally renowned organization focused on the delivery of quality trauma care in the Americas. Panamerican Trauma Society has worked to implement trauma registries in Ecuador, Colombia, ${ }^{13}$ and Panama through the International Trauma System Development Program (ITSDP) at Virginia Commonwealth University (VCU) ${ }^{14}$ The ITSDP headquarters provided administrative support throughout the implementation process.

The full electronic version of the PTS Trauma Registry includes 250 data points. A simplified, essential elements format was chosen for Santa Cruz to better align with local resources and needs for improved adoption. There remains the option for expansion to the full registry version when feasible. The registry is designed to provide a basic description of the injured patient, including patient and injury demographics, vital signs, Glasgow Coma Scale (GCS) score, information on each injury with Abbreviated Injury Scale (AIS) scores, and patient ED and hospital dispositions. The electronic system calculates the Injury Severity Score (ISS), Revised Trauma Score (RTS), Trauma and Injury Severity Score (TRISS), and Kampala Trauma Score (KTS) from information provided in other fields.
The original single-page, two-sided paper data collection form was provided by PTS (Fig. 1, English version). There are a total of 54 separate questions (including the six AIS regions) organized into 18 question categories (Table 1). Questions are a mixture of free text $(n=26)$ and multiple choice questions (MCQs) $(n=28$, including six AIS regions), with those pertaining to injury mechanisms and descriptions allowing more than one answer per patient. Some questions only require answers if applicable to the case being recorded.

\section{Program Development and Training}

Discussions were held with Dr. J. Esteban Foianini, medical director of Clínica Foianini, hospital leadership, and quality management staff, as well as personnel within the Bolivian chapter of the Association of Medical Doctors of Asia (AMDA), to determine the most appropriate registry methodology. The AMDA-Bolivia is a non-profit organization that offers training courses to medical personnel across Bolivia, including ATLS. Their role was to assist with registry logistics and oversight.

Nurses were selected as data collectors for the trauma registry, and the head ED nurse was charged with overseeing and managing the pilot program, including ensuring data quality (i.e., capture of eligible trauma patients and the full completion of registry forms). Training sessions were organized over 2 days. Attendance was required for nurses, with additional medical staff encouraged to attend. Each meeting started with a discussion of trauma definitions and examples, followed by an overview of trauma registries, a detailed examination of the Bolivian trauma registry methodology and data collection form, and a case example for practice. Trauma definitions were borrowed from two prominent trauma organizations, the American Trauma Society (ATS) and the American College of Surgeons Committee on Trauma (ACS-COT). ${ }^{15}$ Anew method for documenting and subsequently identifying trauma patients was created in the nurse electronic charting system by information technology staff. This was done to facilitate the comparison of completed trauma registry forms with eligible patients to determine registry capture rates.

Process feedback from ED nurses and physicians led to alterations in the data collection form during the initial days of implementation. Modifications included changing words that did not reflect the local Spanish dialect, as well as adding previously absent injury mechanisms common to Bolivia, such as dog bites.

\section{Data Collection, Management, and Analysis}

Trauma was defined as any patient presenting with an acute physical injury as described in detail during the 


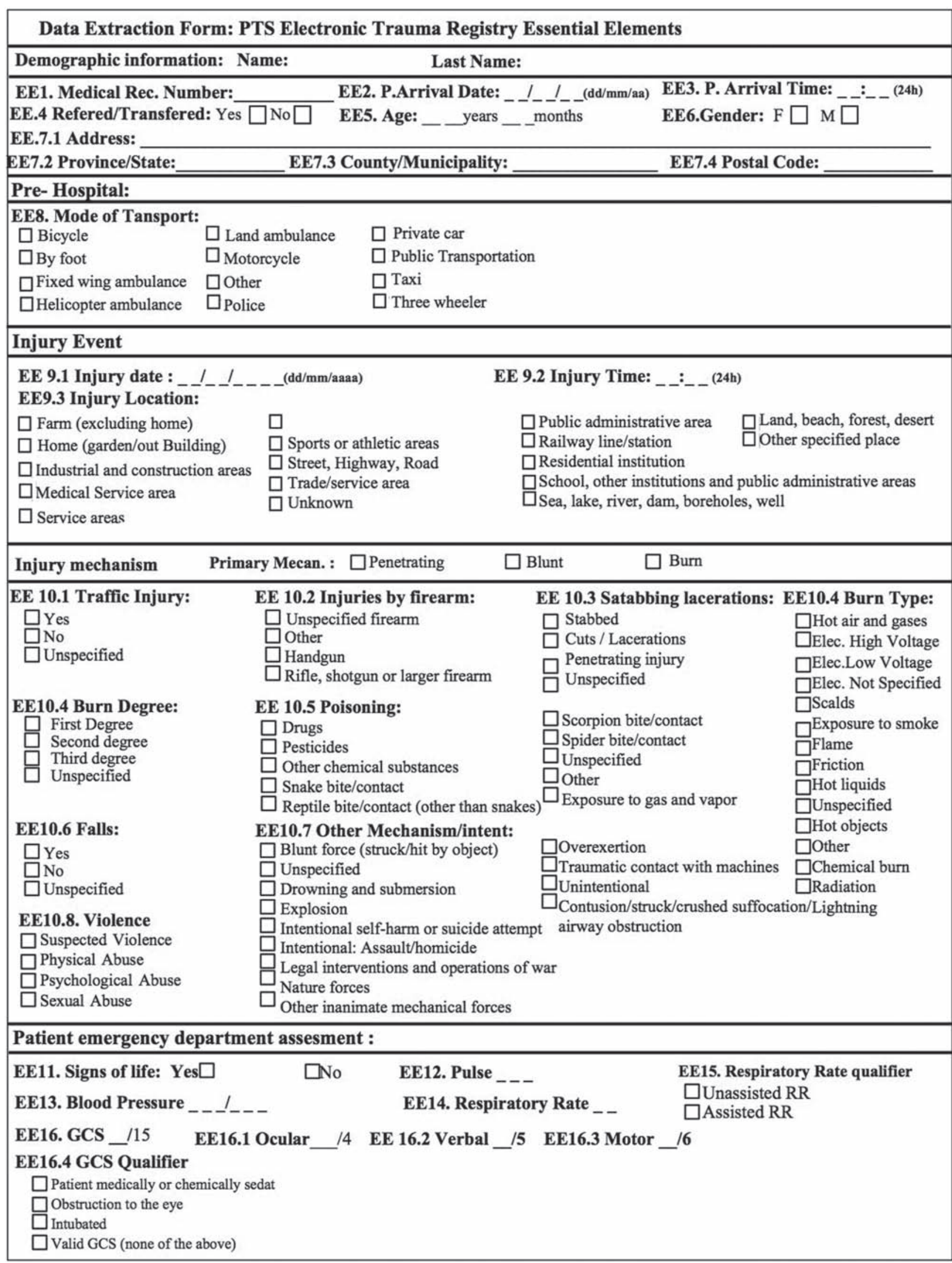

Fig. 1: Trauma Registry Data Collection Form (English Version, January 2015) 
Cont'd...

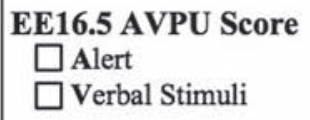

EE17. Body Part injured:

Note the lesions presented in their corresponding body part and / or use the diagram

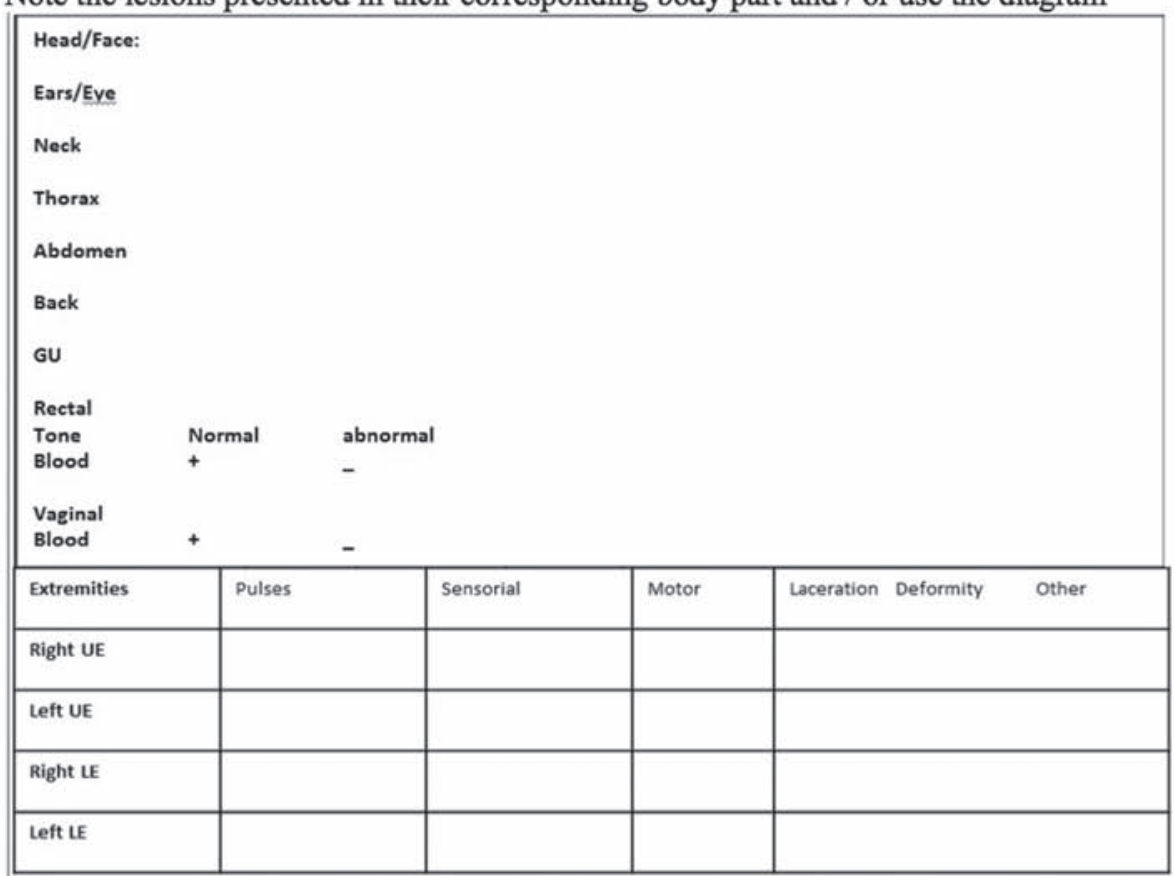

EE.19 AIS (Severity):

EE.19.1 Head

1
2
3
4
5
6
EE.19.2 Face

19.2 Face
1
2
3
4
5
6

$\square$ Painful Stimuli

$\square$ No response

\section{EE17.1 Type of injury:}

EE.19.3 Thorax

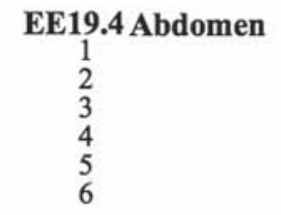

\section{EE16.6 Alcohol Use \\ $\square$ Yes \\ $\square$ No \\ Unspecified}

EE18.No. serious injuries
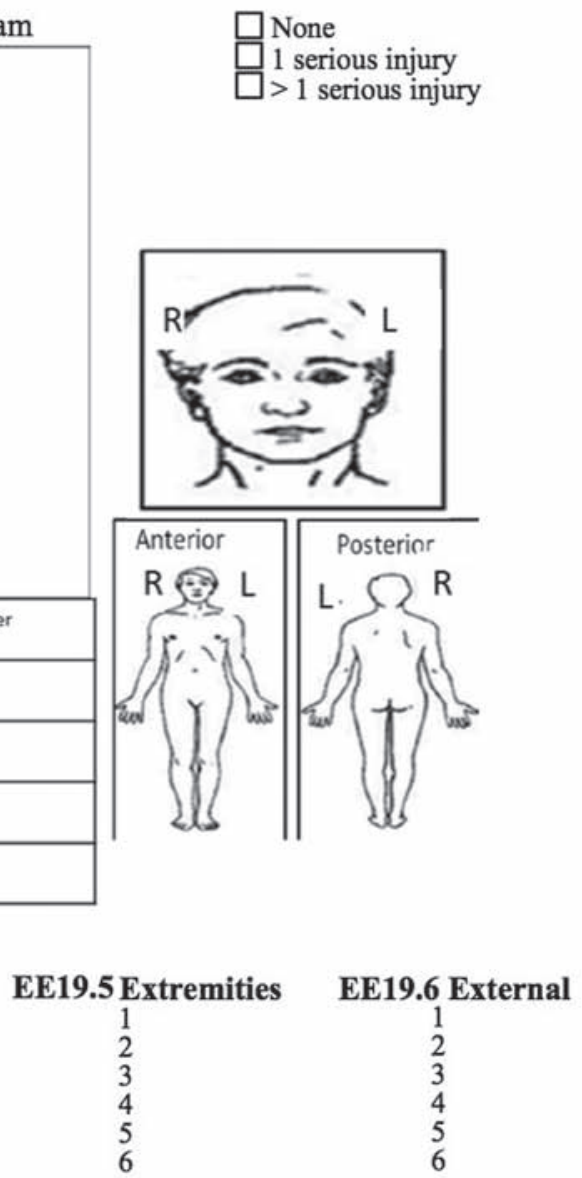

Patient Disposition in the emergency room and in hospitalization:

EE20. ED Disposition

$\square$ Admmited to ICU

$\square$ Admmited to Ward

$\square$ Clinic

$\square$ Dead/Morgue

$\square$ Dead before arrival

$\square$ Discharged

$\square$ Left Against medical advice

$\square$ OR

$\square$ Other

$\square$ Refered to other hospital

$\square$ Unknown

EE23. Patient disposition in hospitalization
$\square$ Dead/Morgue
Discharged
$\square$ Left Against medical advice
$\square$ Other
Refered to other hospital

Unknown

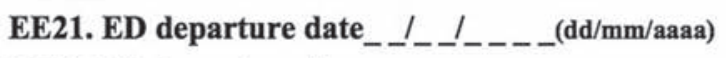

EE22. ED departure time__:_ _ (24h)

EE24. Date of Hospital Discharge:__ _ I _ _ (dd/mm/aaaa)

EE25. Time of Hospital Discharge__:_- (24h)

Data Collectors Name and Signature:

Page 2 
Table 1: Trauma registry response analysis by question

\begin{tabular}{|c|c|c|c|}
\hline \multirow{2}{*}{$\begin{array}{l}\text { Question category } \\
(n=17)\end{array}$} & \multirow[b]{2}{*}{ Questions $^{a}$} & \multicolumn{2}{|c|}{$n(\%)^{b}$} \\
\hline & & Missing & Error \\
\hline \multirow[t]{2}{*}{ Patient identifiers } & Name (first and last - paternal and maternal) & $5(5.5)$ & $0(0.0)$ \\
\hline & Medical record number & $12(13.2)$ & $4(4.4)$ \\
\hline \multirow[t]{2}{*}{ Hospital arrival } & Hospital arrival date & $12(13.2)$ & $0(0.0)$ \\
\hline & Hospital arrival time & $25(27.5)$ & $18(19.8)$ \\
\hline \multicolumn{2}{|l|}{ Referred/transferred } & $40(44.0)$ & $0(0.0)$ \\
\hline \multicolumn{2}{|l|}{ Age } & $6(6.6)$ & $0(0.0)$ \\
\hline \multicolumn{2}{|l|}{ Sex } & $8(8.8)$ & $0(0.0)$ \\
\hline \multirow[t]{2}{*}{ Address } & Street/neighborhood, province, municipality & $39(42.8)$ & $16(17.6)$ \\
\hline & Postal code & $91(100.0)$ & $0(0.0)$ \\
\hline \multicolumn{2}{|l|}{ Mode of transport } & $3(3.3)$ & $0(0.0)$ \\
\hline \multirow[t]{3}{*}{ Injury event information } & Injury date & $0(0.0)$ & $0(0.0)$ \\
\hline & Injury time & $24(26.4)$ & $28(30.8)$ \\
\hline & Injury location & $6(6.6)$ & $0(0.0)$ \\
\hline \multirow[t]{2}{*}{ Injury mechanism } & Primary injury mechanism & $41(45.0)$ & $0(0.0)$ \\
\hline & Specific injury mechanism(s) & $2(2.2)$ & $0(0.0)$ \\
\hline \multirow[t]{5}{*}{ Vital signs } & Signs of life at ED presentation & $3(3.3)$ & $0(0.0)$ \\
\hline & Pulse rate & $12(13.2)$ & $1(1.1)$ \\
\hline & Blood pressure & $20(22.0)$ & $1(1.1)$ \\
\hline & Respiratory rate & $25(27.5)$ & $1(1.1)$ \\
\hline & Respiratory rate qualifier & $56(61.5)$ & $0(0.0)$ \\
\hline \multirow[t]{2}{*}{ Glasgow Coma Scale } & GCS score & $15(16.5)$ & $1(1.1)$ \\
\hline & GCS qualifier & $48(52.7)$ & $0(0.0)$ \\
\hline \multicolumn{2}{|c|}{ Alert/Verbal/Pain/Unresponsive (AVPU) } & $19(20.9)$ & $0(0.0)^{c}$ \\
\hline \multicolumn{2}{|c|}{ Alcohol use } & $83(91.2)$ & $0(0.0)$ \\
\hline \multirow[t]{2}{*}{ Injury description } & Location of injury(ies) & $4(4.4)$ & $0(0.0)$ \\
\hline & Type of injury(ies) & $10(11.0)$ & $17(18.7)$ \\
\hline \multicolumn{2}{|l|}{ Number of serious injuries } & $81(89.0)$ & $0(0.0)$ \\
\hline \multirow[t]{3}{*}{ ED disposition } & ED disposition & $23(25.3)$ & $0(0.0)$ \\
\hline & ED disposition date & $57(62.6)$ & $0(0.0)$ \\
\hline & ED disposition time & $65(71.4)$ & $1(1.1)$ \\
\hline \multirow[t]{3}{*}{ Hospital disposition } & Hospital disposition & $70(76.9)$ & $0(0.0)$ \\
\hline & Hospital disposition date & $60(65.9)$ & $0(0.0)$ \\
\hline & Hospital disposition time & $63(69.2)$ & $4(4.4)$ \\
\hline
\end{tabular}

a Bolded questions are multiple choice; non-bolded questions are free-text; ${ }^{\mathrm{b}} \%$ of 91 forms; ${ }^{\mathrm{c}}$ Many participants selected multiple answers; the highest alertness level was used

staff training sessions, including blunt, penetrating, burn, drowning, or poisoning mechanisms, and others. This broad definition was used to ensure the capture of all patients with qualifying diagnoses, since International Classification of Disease (ICD) codes are not routinely used at the time of the clinical encounter. Unlike in many trauma registries, hospital admission was not used as an inclusion criterion. This enabled the largest representation of injuries occurring in the community, and was based on the observation that hospital admissions do not always occur when needed due to resource limitations.

Data collection took place during the patient's initial presentation to the ED. Completed and signed forms were photocopied, with one copy placed in the patient's chart and the other in a secure lock box. Those in the lockbox were periodically brought to medical records, scanned, and then maintained in a secure file cabinet for later entry into the electronic system. The copy in the patient's chart was to be finished at hospital discharge for completion of the record. Due to the complexity of AIS calculations, this section (EE19.1-EE19.6, Fig. 1) was excluded from the pilot program.

The head ED nurse was assigned the task of ensuring form completeness and enrollment of all qualifying trauma patients. Missing data was to be extracted from existing medical charts. Signs were posted throughout the ED as a reminder. Intermittent registry oversight was maintained by an out-of-country project lead via email contact with the head ED nurse, Clinica Foianini staff, and AMDA-Bolivia personnel.

At the conclusion of the pilot study, forms were reviewed and data were entered into an Excel spreadsheet. Variables were grouped and assessed for missing information, or misinterpretations and formatting 
Implementation of a Hospital-based Trauma Registry in Santa Cruz de la Sierra, Bolivia

errors. The nine specific injury mechanism questions (EE 10.1-10.7, Fig. 1) were collapsed into one category, with only those forms without a selected answer in all nine categories recorded as missing. All components of a patient's address, including street/neighborhood, province/state and county / municipality, were necessary to be considered complete. Injury and discharge times were considered erroneous if they occurred after or prior to the hospital arrival time respectively. Missing and erroneous answers were separately summed across all subjects by question type (free text, MCQ, and all). The average number of missing answers, erroneous responses, and total problems (missing and erroneous combined) were calculated per question (26 free text, 22 MCQs, and 48 total) and per form (91 forms). Forms were also reviewed for preliminary injury demographic results; improperly formatted responses were removed prior to analysis.

An ICD-10 diagnosis code search within the hospital's electronic charting and billing system was performed to collect the total number of registry-qualifying patients between January 15th and September 15th, 2015. Codes provided by Clínica Foianini were available to one decimal point and spanned from S00-T88, excluding superficial injuries, foreign bodies, or those determined to not be traumatic injuries by one of the authors (MAB). Only the first hospital visit for a given injury was counted.

\section{RESULTS}

The pilot trauma registry program at Clínica Foianini produced 91 forms over 8 months. The ICD-10 code search revealed 142 different diagnoses in 2,816 patients eligible for registry inclusion, with a resultant registry capture rate of $3.2 \%$. The most common ICD-10 diagnosis codes are shown in Graph 1. Those identified as eligible for inclusion via ICD-10 code search but without registry forms at the pilot study's conclusion were not retrospectively included due to the large population size.

In a separate activity, the newly designed trauma patient designation method within the nurse electronic charting system had 100 patients marked as "traumas." However, there were discrepancies between those marked as "traumas" and those with registry forms. Eight patients marked as "traumas" did not have an accompanying form, and nine patients with forms were listed twice in the electronic system, with each entry corresponding to a different insurance but only a single hospital visit.

\section{Question Analysis}

Many forms were missing critical data, with average omissions of 12.5 per form (26\% of questions) and 23.7
Table 2: Trauma registry response analysis by question type

\begin{tabular}{lllll}
\hline \multirow{2}{*}{ Form problem } & \multicolumn{3}{c}{ Question type $^{\mathrm{a}}$} \\
\cline { 3 - 5 } Missing & Total & 653 & 483 & 1,136 \\
& Per question & 25.1 & 21.9 & 23.7 \\
& Per form & 7.2 & 5.3 & 12.5 \\
\multirow{2}{*}{ Error } & Total & 95 & 0 & 95 \\
& Per question & 3.6 & 0 & 2.0 \\
\multirow{3}{*}{ Total } & Per form & 1.0 & 0 & 1.0 \\
(Missing + & Total & 748 & 483 & 1,231 \\
Error) & Per question & 28.8 & 21.9 & 25.6 \\
& Per form & 8.2 & 5.3 & 13.5 \\
\hline
\end{tabular}

${ }^{\mathrm{a}}$ Free text: $\mathrm{n}=26$ questions; Multiple choice: $\mathrm{n}=22$ questions, excluding six AIS questions

per question ( $26 \%$ of subjects), most commonly in the injury description, and final ED and hospital disposition categories (Tables 1 and 2). There were also varying levels of misinterpreted questions or incorrectly formatted answers, which averaged 1.0 per form ( $2.1 \%$ of questions) and 2.0 per question (2.2\% of subjects) (Table 2$)$. Nearly all interpreted medical record number to mean admission number, the latter of which is not unique for each patient but instead is assigned in chronological order per visit and resets each January. Hospital arrival and injury times were often reported as transit time rather than actual times of occurrence. The option to report age in months occasionally caused confusion. Some only listed total GCS score without specifying ocular (26.4\% missing), verbal (25.3\% missing), or motor (25.3\% missing) components. Two of five factors required to calculate the KTS proved problematic: Many checked multiple boxes for the Alert/ Verbal/Pain/Unresponsive (alert, responds to verbal stimuli, responds to painful stimuli, and unresponsive) system; and most failed to provide the number of serious injuries. More errors are listed in Table 1. Overall, MCQs were less prone to missing information or errors than freetext responses (Table 2). Of note, select forms did include detailed additional notes that aided in determining diagnoses and supplementing other missing pieces of information.

\section{Patient Results}

Of the 91 patients with completed trauma registry forms, a majority were male (59.3\%) and in their mid-20s. Most presented to the hospital on the same day of the injury $(82.4 \%)$, with many arriving either by private car (38.5\%) or ambulance $(27.5 \%)$. Visits occurred in every month from January to September, with the largest number in July ( $\mathrm{n}=19)$, and the most common hospital arrival time from 8:00 to $15: 59$ (22.0\%). Head contusion was the most frequent injury type and location (19.8\%), followed by penetrating/lacerating upper extremity (11.0\%) and head 


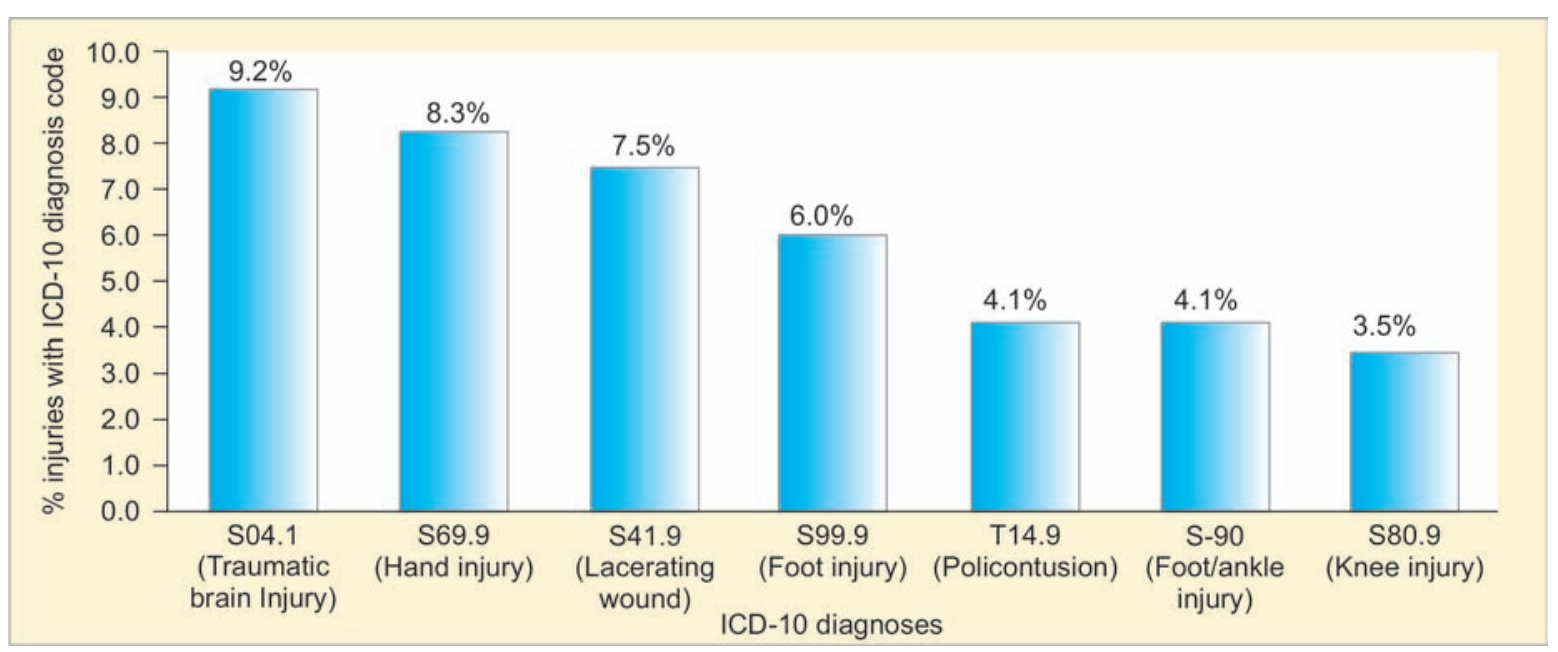

Graph 1: Most Common Trauma ICD-10 Code Diagnoses at Clínica Foianini (Jan-Sep 2015)

(7.7\%) wounds, and upper extremity fractures (6.6\%). These results generally reflect the distribution of ICD-10 diagnosis codes from the hospital records search (Graph 1). Further trauma patient results are provided in Table 3.

\section{DISCUSSION}

This pilot program in Santa Cruz is the first publication to describe the implementation of a hospital-based trauma registry in Bolivia, and highlights facilitators and barriers to obtaining reliable data. Most eligible trauma patients went unregistered, and those who were captured frequently had incomplete forms. Patient information that was collected, however, exemplifies how valuable these data can be for evidence-based pre-hospital and hospital service planning, and effective injury prevention strategies. Lessons learned through examining methodology, implementer feedback, and preliminary results suggest many possible targets to improve the program and enable further successful expansion, mainly involving oversight, education, and training.

One possible explanation for the registry's low trauma patient capture rate is the many differing definitions of trauma throughout the world. For example, many Clínica Foianini staff initially interpreted the word as applying solely to those injuries treated by a traumatólogo (orthopedic surgeon), thus excluding many additional injury mechanisms and types. A handful of studies have sought to examine perceptions of medical emergencies, and how this influences ED and primary care utilization ${ }^{16-19}$; however, the literature lacks similar studies on perceptions of trauma and how this could influence registry data collection. Preliminary results from a qualitative analysis of perceptions of trauma in Santa Cruz via focus groups and interviews showed varied interpretations of trauma among health care personnel, first responders, and community members (unpublished data). The registry training sessions sought to tackle this challenge through the provision of one clear definition of trauma, supported by multiple examples of qualifying mechanisms. Future aims include incorporating local feedback to better elucidate this theme, thereby increasing the capture of eligible patients in the registry.

The Bolivian health care system is still in the early stages of developing a "culture of information," defined as "the capacity and control to promote values and beliefs among members of an organization by collecting, analyzing, and using information to accomplish the organization's goals and mission." ${ }^{20}$ The system currently lacks reliable health information and surveillance systems, widespread quality improvement (QI) programs, or thorough documentation of patient encounters, all of which likely to affect the results of this pilot study (Bolivian physicians, personal communication, Fall 2015). Building a culture of data-driven improvements should preferentially start with individual and organizational behavior change. Adjustments, such as these would take time and often progress in a stepwise fashion, as described by the Plan, Do, Study, Act cycle for QI. ${ }^{21}$ A strategic implementation climate requires those performing the registry work to understand the value of the program, which includes highlighting gaps in injury burden and trauma care between Bolivia and other settings, and using the discrepancy to motivate change. Additional mechanisms include recognition of accurate, complete, and timely registry form completion, the solicitation of implementer feedback for process improvement, and the clarification of abstract concepts, such as injury severity scoring. Further incentive is provided by regularly reporting individual hospital and overall system registry progress, making incountry program leaders available for timely resolution of issues, and promoting and facilitating implementers' pursuit of academic projects based on registry data. ${ }^{21}$ The implementation of the pilot registry at Clínica Foianini 


\begin{tabular}{|c|c|c|c|}
\hline Characteristic & & $n$ & $\%^{b}$ \\
\hline Sex & Male & 54 & 59.3 \\
\hline Age (years) ${ }^{c}$ & 27 & $(12,44)$ & \\
\hline Referred/transferred & Yes & 14 & 15.4 \\
\hline \multirow[t]{4}{*}{ Mode of transport } & Private car & 35 & 38.5 \\
\hline & Ambulance & 25 & 27.5 \\
\hline & On foot & 11 & 12.1 \\
\hline & Other $^{\mathrm{d}}$ & 20 & 22.0 \\
\hline $\begin{array}{l}\text { Hospital arrival } \\
\text { time }(24 \text { hours })^{c}\end{array}$ & & $12: 58$ & $(07: 13,17: 25)$ \\
\hline \multirow[t]{3}{*}{ Injury location } & Road/highway & 29 & 31.9 \\
\hline & Home & 21 & 23.1 \\
\hline & Other ${ }^{\mathrm{e}}$ & 41 & 45.0 \\
\hline \multirow{4}{*}{$\begin{array}{l}\text { Primary injury } \\
\text { mechanism }\end{array}$} & Penetrating & 8 & 8.8 \\
\hline & Blunt & 37 & 40.7 \\
\hline & Burns & 2 & 2.2 \\
\hline & Other $^{f}$ & 44 & 48.3 \\
\hline \multirow{3}{*}{$\begin{array}{l}\text { Specific injury } \\
\text { mechanism }^{9}\end{array}$} & Transit & 35 & 38.5 \\
\hline & Fall & 46 & 50.5 \\
\hline & Other $^{h}$ & 20 & 22.0 \\
\hline \multirow{4}{*}{$\begin{array}{l}\text { Location of } \\
\text { injury(ies) }{ }^{g}\end{array}$} & Upper extremity & 40 & 44.0 \\
\hline & Head & 32 & 35.2 \\
\hline & Face & 13 & 14.3 \\
\hline & Other ${ }^{i}$ & 36 & 34.0 \\
\hline \multirow[t]{5}{*}{ Type of injury(ies) ${ }^{g}$} & Contusion & 29 & 31.9 \\
\hline & $\begin{array}{l}\text { Laceration/ } \\
\text { Penetrating }\end{array}$ & 21 & 23.1 \\
\hline & Fracture & 14 & 15,4 \\
\hline & Poly-trauma & 11 & 12.1 \\
\hline & Other $^{j}$ & 30 & 33.0 \\
\hline Signs of life in ED & Yes & 87 & 95.6 \\
\hline Pulse rate ${ }^{c}$ & & 87 & $(76,100)$ \\
\hline Blood pressure $^{c}$ & & $123 / 77$ & $\begin{array}{l}(110 / 66 \\
135 / 84)\end{array}$ \\
\hline Respiratory rate $^{c}$ & & 20 & $(20,23)$ \\
\hline $\begin{array}{l}\text { Glasgow Coma } \\
\text { Score }(\text { GCS })^{c}\end{array}$ & & 15 & $(15,15)$ \\
\hline \multirow[t]{4}{*}{ AVPUk score } & Alert & 62 & 68.1 \\
\hline & Verbal & 3 & 3.3 \\
\hline & Pain & 5 & 5.5 \\
\hline & Unresponsive & 2 & 2.2 \\
\hline \multirow[t]{4}{*}{ ED disposition } & Home & 23 & 25.3 \\
\hline & $\begin{array}{l}\text { Hospital } \\
\text { admission }\end{array}$ & 21 & 23.1 \\
\hline & ICU admission & 17 & 18.7 \\
\hline & Other ${ }^{\prime}$ & 30 & 33.0 \\
\hline
\end{tabular}

ancluded questions with at least $50 \%$ response rate; ${ }^{\mathrm{b}} \%$ of total $\mathrm{n}=$ 91 registry forms; ' ${ }^{\circ}$ Median (IQR); ${ }^{\mathrm{d} B i c y c l e, ~ m o t o r c y c l e, ~ t a x i, ~ p u b l i c ~}$ transportation, other, blank; ${ }^{\mathrm{e}}$ Public/administration area, commercial/ service area, sports/athletic area, trade/service area, industrial/construction area, school, residential institution, unknown/unspecified, open land, other, blank; ${ }^{f}$ Penetrating and blunt, blank; ${ }^{9} \%>100$ because more than one injury mechanism/location/type allowed per person; ${ }^{\mathrm{h} F i r e a r m, ~ k n i f e, ~ b u r n, ~ p o i s o n i n g, ~ e x p l o s i o n, ~ m a c h i n e, ~ a i r w a y, ~}$ unspecified, mechanical force, blank; 'Abdomen, lower extremity, back/ neck, pelvis, thorax, blank; 'Amputation, deformity, excoriation, penetrating injury, burns, blank; ${ }^{\mathrm{k}}$ Alert/Verbal/Pain/Unresponsive (AVPU) system; 'Morgue, left against medical advice, operating room, referred to other hospital, blank

employed a select few of these approaches, with others now providing a path for improvement to help ensure program sustainability and success.

Methodological challenges to sustainable trauma registries in low-resource settings are numerous, yet detailed descriptions of barriers and solutions appear infrequently in the literature. A 2006 review article described similar obstacles as those experienced at Clínica Foianini, such as inadequate population-level data, lack of community awareness, lack of standardized hospital data-collection systems, and low capture of eligible trauma cases within the registry suggesting questionable quality and completeness. This group also mentioned inadequate funding and unsupportive existing health policy, ${ }^{22}$ neither of which proved to be significant challenges in Bolivia at this stage. In a subsequent review of trauma registries in LMICs, O'Reilly et al ${ }^{5}$ noted that a majority did not use advanced methods for analyzing missing data, despite suggesting this is a frequent occurrence. Experiences from Kenya overlapped with challenges seen in Bolivia, with Stevens et $\mathrm{al}^{23}$ going a step further to couple descriptions of their setbacks with suggestions for possible QI interventions. Lessons learned were also the focus of a recent qualitative study of trauma registrar experiences from both developed and developing countries. ${ }^{24}$ Highlighting challenges and possible solutions to trauma registry implementation in resource-challenged settings is essential for creating a repository of context-relevant methodologies, ideally resulting in more reliable data from LMICs.

Regarding study limitations, using the ICD-10 code search to determine the overall trauma-registry-eligible population can prove problematic, as patients are only allowed one diagnosis in the electronic charting system at Clínica Foianini. Therefore, not all injuries are captured if a patient presents with multiple lesions, and those who present with co-morbid, nontrauma conditions may also be missed. Furthermore, the current system at Clínica Foianini does not easily differentiate between initial and follow-up visits, requiring manual sorting of patients to identify the first presentation. Finally, the ICD-10 codes utilized at Clínica Foianini only extend to one decimal point, limiting the specificity and utility of the diagnoses. An ongoing transition to a full electronic medical record at Clínica Foianini will ideally address many of these issues, and lead to more accurate patient data in the future.

A limitation of all hospital-based trauma registries, especially in LMICs like Bolivia, is that many injured patients do not survive to reach the hospital or do not seek treatment at health facilities. Therefore, these registries do not always provide an accurate representation of the injury burden within the population. ${ }^{22}$ Increasing registry facility sites, particularly at second-level, rural hospitals, as well 
as incorporating data from first responder groups and the morgue, can provide a more accurate picture. Additionally, this study is limited in making conclusions regarding injury burden, given the overall low trauma patient capture rate, incomplete data collection, and lack of injury severity ratings. However, these flaws highlight targets for process improvement, with the possibility of future injury analyses and projections once data quality improves.

\section{CONCLUSION}

Early efforts at implementing a paper-based trauma registry at a private hospital in the city of Santa Cruz de la Sierra, Bolivia suggest that with the necessary training, oversight, and adaptations, a sustainable registry program is feasible at both this site and others. Building off of lessons learned from this pilot study, the registry program continued at Clínica Foianini and expanded to four additional public hospitals in Santa Cruz in late 2015. Modifications for improved sustainability at all five sites included the addition of an in-country registry program leader, dedicated to managing training, monitoring compliance, and resolving problems as they arose, as well as regular meetings between hospital leaders and local health department officials to report on registry progress and to cooperatively tackle any perceived barriers to success. Long-term objectives include making the registry a standard program at all levels of health facilities throughout Santa Cruz and eventually Bolivia. Strategies used in these registry implementation efforts can ideally be applied to similar LMIC settings, thereby increasing the availability of reliable global trauma data. This information will empower decision-makers to make evidence-based choices regarding the allocation of resources for initiatives to prevent injuries, improve trauma care, and save lives.

\section{CLINICAL SIGNIFICANCE}

The results from this study add meaningful insights to the literature on registry and health information system implementation in LMICs. This material will serve to inform and further develop the Bolivian program, and can also be applied to comparable initiatives in similar settings, ideally helping create more sustainable health information systems in LMICs.

\section{ACKNOWLEDGMENTS}

This study received funding from a Johns Hopkins Bloomberg School of Public Health Master of Public Health Field Experience Fund Award, the NU Feinberg School of Medicine Post-Graduate Fellowship in Global Health, and the Arthur Tracy Cabot Fellowship at the Center for Surgery and Public Health, Brigham and
Women's Hospital, Harvard T. H. Chan School of Public Health, and Harvard Medical School. The study received Institutional Review Board Approval from NU Feinberg School of Medicine, and local Bolivian approval from Clínica Foianini and the Autonomous Department of Santa Cruz Secretary for Health and Social Policy. This study would not have been possible without the dedicated efforts of Clinica Foianini staff, especially the ED nurses and their leader Ingrid Becerra Brito, all of who served as local champions of the program.

\section{REFERENCES}

1. GBD 2013 Mortality and Causes of Death Collaborators. Global, regional, and national age-sex specific all-cause and cause-specific mortality for 240 causes of death, 1990-2013: a systematic analysis for the Global Burden of Disease Study 2013. Lancet 2015 Jan 10;385(9963):117-171.

2. WHO. Injuries and violence: the facts. Geneva: World Health Organization; 2010.

3. WHO. Global status report on road safety 2015. Geneva: World Health Organization; 2015.

4. Moore L, Clark DE. The value of trauma registries. Injury 2008 Jun;39(6):686-695.

5. O'Reilly GM, Joshipura M, Cameron PA, Gruen R. Trauma registries in developing countries: a review of the published experience. Injury 2013 Jun;44(6):713-721.

6. Bolivia: The World Bank Group; 2014 [cited 2014]. Available from: http://data.worldbank.org/country/bolivia.

7. PAHO. Health in the Americas. 2012 ed. Country Volume. Bolivia: Pan American Health Organization; 2012.

8. WHO. Global status report on road safety 2013. Geneva: World Health Organization; 2013.

9. IHME. Country profile: Bolivia [cited 2015 Sep 30]. Seattle (WA): Institute for Health Metrics and Evaluation (IHME); 2015. Available from: http://www.healthdata.org/bolivia.

10. Anuario Estadístico 2012. Bolivia: Instituto Nacional de Estadistica; 2012.

11. Santa Cruz. Bolivia: Instituto Nacional de Estadistica; 2015.

12. Bolivia country profile [cited 2015]. B.B.C. News; 2012. Available from: news.bbc.co.uk/2/hi/americas/country_ profiles/1210487.stm.

13. Ordonez CA, Pino LF, Tejada JW, Badiel M, Loaiza JH, Mata LV, Aboutanos MB. Experience of two first level hospitals in the southwest region of Colombia on the implementation of the Panamerican Trauma Society International Trauma Registry. Rev Col Bras Cir 2012 Jul-Aug;39(4):255-262.

14. Panamerican Trauma Society. Trauma registry: improving trauma care in the Americas. Panamerican Trauma Society [cited 2016 Jun 6]. Available from: http://www.panamtrauma. org/page-1854397.

15. Report of the Michigan Statewide Trauma Care Commission. Michigan: State of Michigan, Michigan Department of Consumer \& Industry Services, Bureau of Health Services, 2002 Nov.

16. Wilkin HA, Tannebaum MA, Cohen EL, Leslie T, Williams N, Haley LLJr. How community members and health professionals conceptualize medical emergencies: implications for primary care promotion. Health Educ Res 2012 Dec;27(6):1031-1042.

17. Langdorf MI, Bearie BJ, Kazzi AA, Blasko B, Kohl A. Patients' vs. physicians' assessments of emergencies: the prudent 
layperson standard. Cal J Emerg Med 2003 Nov-Dec;4(4): 75-81.

18. Li J, Galvin HK, Johnson SC. The "prudent layperson" definition of an emergency medical condition. Am J Emerg Med 2002 Jan;20(1):10-13.

19. Derlet RW, Ledesma A. How do prudent laypeople define an emergency medical condition? J Emerg Med 1999 MayJun;17(3):413-418.

20. Aqil A, Lippeveld T, Hozumi D. PRISM framework: a paradigm shift for designing, strengthening and evaluating routine health information systems. Health Policy Plan 2009 May;24(3):217-228.

21. Aarons GA, Horowitz JD, Dlugosz LR, Ehrhart MG. The role of organizational processes in dissemination and implemen- tation research. In: Brownson RC, Colditz GA, Proctor EK, editors. Dissemination and implementation research in health. New York (NY): Oxford University Press; 2012. p. 128-153.

22. Nwomeh BC, Lowell W, Kable R, Haley K, Ameh EA. History and development of trauma registry: lessons from developed to developing countries. World J Emerg Surg 2006 Oct 31;1:32.

23. Stevens KA, Paruk F, Bachani AM, Wesson HH, Wekesa JM, Mburu J, Mwangi JM, Saidi H, Hyder AA. Establishing hospital-based trauma registry systems: lessons from Kenya. Injury 2013 Dec;44 Suppl 4:S70-S74.

24. O'Reilly GM, Gabbe B, Braaf S, Cameron PA. An interview of trauma registry custodians to determine lessons learnt. Injury 2016 Jan;47(1):116-124. 


\section{The Implementation of a Hospital-based Trauma Registry in Santa Cruz de la Sierra, Bolivia: Methodology, Preliminary Results, and Lessons Learned}

There is an enormous burden of injury in low- and middle-income countries (LMIC) that needs to be defined in its magnitude and the nature before preventive interventions and improvements in trauma care can be successfully implemented. Unfortunately, this is easier said than done, as is shown by many investigators in several LMIC. The Pan American Trauma Society (PTS), with assistance from the International Trauma System Development Program (ITSDP) at Virginia Commonwealth University (VCU) has developed a Trauma Registry for this purpose and implemented them in countries, such as Ecuador, Colombia, and Panama. Another exciting initiative of PTS is the PTS/CSPH Trauma Surgery Research Fellowship (TSRF), a joint collaborative program between the PTS and the Center for Surgery and Public Health (CSPH) at Brigham and Women's Hospital. It is a funded fellowship in health services research (HSR), addressing issues central to managing and caring for critically ill and injured surgical patients in Latin America. Under the mentorship of CSPH faculty researchers, especially Dr Adil Hyder, the PTS/ CSPH Fellow will pursue innovative research projects in areas relevant to trauma surgery in Latin America.

The present manuscript is the result of excellent work by our resident member, Dr Boeck. It is funded by multiple institutions: Johns Hopkins Bloomberg School of Public Health, Master of Public Health Field Experience Fund Award, the NU Feinberg School of Medicine Post-Graduate Fellowship in Global Health (Dr Swaroop), and the Arthur Tracy Cabot Fellowship at the Center for Surgery and Public Health, Brigham and Women's Hospital, Harvard T. H. Chan School of Public Health, and Harvard Medical School (Dr A. Hyder). A MPH from JH-B School of Public Health and a surgical resident of Columbia University, Dr Boeck carried out this outstanding work in Santa Cruz, Bolivia under the close guidance and mentorship of Dr Esteban Foainini.

The importance of this study is very evident: It adds to our knowledge the role of trauma registries in LMIC and supplements the work done in Africa, Latin America, and Asia. ${ }^{1,2}$ It provides a basic framework for registry development in regions like Bolivia. The knowledge and the lessons learnt can be expanded to similar initiatives in the rest of Latin America. It substantiates the words of Margaret Chan, Director General of WHO, "[t]he real need (in global health) is to close the data gaps, especially in low and middle-income countries, so that we no longer have to rely heavily on statistical modelling for data on disease burden." ${ }^{3}$

The PTS looks forward to other researchers and centers following this pioneering example.

\section{REFERENCES}

1. O'Reilly GM, Joshipura M, Cameron PA, Gruen R. Trauma registries in developing countries: a review of the published experience. Injury 2013 Jun;44(6):713-721.

2. Stevens KA, Paruk F, Bachani AM, Wesson HH, Wekesa JM, Mburu J, Mwangi JM, Saidi H, Hyder AA. Establishing hospital-based trauma registry systems: lessons from Kenya. Injury 2013 Dec;44(Suppl 4):S70-S74.

3. Riviello R, Scott JW. Closing the data gaps for surgical care delivery in LMICs. Lancet Global Health 2016 Mar;4(3):e138-e139. 